\title{
Asymmetric Dimethylarginine Measurement
}

National Cancer Institute

\section{Source}

National Cancer Institute. Asymmetric Dimethylarginine Measurement. NCI Thesaurus.

Code $C 158233$.

The determination of the amount of asymmetric dimethylarginine present in a sample. 